\title{
A Case of Zolpidem-Induced Sleep-Related Eating Disorder
}

\author{
Jihye Hwang, Gha-Hyun Lee and Sang-Ahm Lee \\ Department of Neurology, Asan Medical Center, University of Ulsan College of Medicine, Seoul, Korea
}

\section{졸피뎀 유발성 수면관련먹기장애}

황지혜, 이가현, 이상암

울산대학교 의과대학 서울아산병원 신경과학교실

Received April 3, 2012

Revised May 27, 2012

Accepted May 27, 2012

Address for correspondence

Sang-Ahm Lee, MD, PhD

Department of Neurology,

Asan Medical Center,

University of Ulsan

College of Medicine,

88 Olympic-ro 43-gil,

Songpa-gu, Seoul 138-736, Korea

Tel: +82-2-3010-3445

Fax: +82-2-474-4691

E-mail: salee@amc.seoul.kr
Sleep related eating disorder (SRED) is a parasomnia with recurrent episodes of involuntary eating during an arousal from nighttime sleep with adverse consequences. The mechanism of SRED is still uncertain but it has been suggested to be related to dopaminergic dysfunction. A few cases of SREDs in association with zolpidem have been reported worldwide, but not yet reported in Korea. We report zolpidem-induced SRED in a patient with underlying restless leg syndrome, periodic leg movement and obstructive sleep apnea.

J Korean Sleep Res Soc 2012;9:15-18
수면관련먹기장애(Sleep related eating disorder, SRED) 는 수면 중 음식물을 섭취하기 위해 수면 시작 3시간 이내에 부분적 또는 완전한 각성이 일어나는 사건수면의 하나다. ${ }^{1}$ 이 질환의 $63 \%$ 의 환자에서 수면 중 주기사지운동(periodic leg movement during sleep, PLMS)이 동반되어 있으며 ${ }^{2}$ $\mathrm{SRED}$ 와 PLMS 두 질환 모두 도파민 투여시 증상이 호전되 기 때문에 SRED의 병리기전에 도파민 시스템이 관련되어 있는 것으로 생각하고 있다. 2002년 Morgenthaler와 Silber ${ }^{3}$ 가 특이적으로 졸피뎀 사용 이후 SRED가 발생하고, 졸피뎀 사용 중단시 증상이 호전된 다섯 명의 환자 증례를 처음 보 고하였다. 국내에서는 지금까지 졸피뎀 유발성 수면관련먹 기장애가 보고된 바가 없어 처음으로 본 증례를 보고한다.

\section{증 례}

47세 남자환자가 수면 중 일어나서 무의식 중에 먹는 증상 을 주소로 내원하였다. 30년 전부터 코골이가 있었으며 20년 전부터 불면증이 발생하였다. 2005년부터는 사업문제와 불
면으로 인한 스트레스, 불안감과 우울증으로 지역 개인 의원 에서 약을 처방받아 복용하고 있었고, 2009년 2월부터 불면 증이 심해져서 수면 전 Zolpidem CR $6.25 \mathrm{mg}$, Wellbutrin XR $300 \mathrm{mg}$, Seroquel $25 \mathrm{mg}$ 를 복용하기 시작했다. 환자는 약을 복용한지 6 개월 이후부터 수면 중 각성이 일어나 무의 식 중에 먹는 증상이 발생하였다. 이런 증상은 수면 시작 후 2 시간 정도 지난 후에 발생하였고 밤사이 주로 한 번의 증상 이 발생하였다. 횟수는 적게는 주 2회에서 심할 때는 거의 매 일 반복되었다.

환자는 수면 중 섭식 문제 발생시 걸어 다닐 만큼 깨어 있 기는 하나 완전히 깨어 있는 상태는 아니고, 옆에서 물으면 비교적 적절히 대답은 하나 잠에 취한 듯 보이는 모습이라고 하였다. 음식을 먹고 있을 때는 본인이 먹고 있다는 느낌을 느끼는 경우가 간혹 있고, 아침에 일어나면 상대방과 한 대화 는 기억을 못하나 음식을 먹었다는 사실은 어렴풋이 기억을 할 때도 있었다. 주로는 아침에 일어나서 음식을 먹고 난 흔 적이 있어 본인이 자던 중에 음식을 먹었다는 사실을 알게 되 었다. 환자는 배고파서 먹는 것은 분명히 아니라고 하였고 주 
로 어떤 음식을 먹는지, 어느 정도의 양을 먹는지는 기억을 하지 못하였다. 요리를 하거나 불이나 칼을 사용하는 일은 없 으며 수면 중 섭식 증상으로 인해 사고가 발생한 경험도 없었 다. 밤사이 음식을 먹는 것 때문에 아침에 일어나면 식욕부진 이 있고 증상 발생 이후에 몸무게가 $5 \sim 6 \mathrm{~kg}$ 증가하였다.

그 외에 다리의 불편한 느낌을 동반하며 다리를 움직이고 싶은 충동을 느끼고 이것이 자기 전이나 또는 가만히 있을 때 악화되는 하지불안증후군(restless leg syndrome, RLS)의 증 상을 호소하였다. 졸피뎀을 복용하기 전부터 이런 RLS 증상 이 거의 매일 있었고, 이 증상으로 인한 입면시 불면증을 호 소하였다. 보호자 관찰 보고에 따르면 밤새도록 두 다리를 움 직인다고 하여 PLMS도 의심되는 소견이 있었으나 이로 인 해 수면 중 각성이 일어나지는 않는다고 하였다. 낮 동안에도
하루 종일 피곤하고 졸리운 주간과다졸림증 호소하였다.

환자는 당시 $178 \mathrm{~cm}, 78 \mathrm{~kg}$ 로 $\mathrm{BMI} 23.3$ 이었고 계통문진과 신체 검진에서 이상소견 없었고 다른 신경학적 이상은 보이 지 않았으며 과거력상 특이 병력은 없었다.

수면다원검사상 총 수면시간은 361.3분이었고 수면 구조에 서 NREM 수면 1단계가 27.1\%로 증가하고 서파수면이 $1.7 \%$ 로 감소하였으며 무호흡저호흡지수(apnea hypopnea index) 는 18.6/h로 중등도의 폐쇄수면무호흡증후군이 관찰되었다. PLMS 지수는 18.4/hr, PLMS 각성지수는 $12.7 / \mathrm{hr}$ 였다(Fig. 1). 수면다원검사 중 환자는 수면 시작 34분에 NREM 2단계 수면에서 침대에서 일어나 앉은 채로 준비한 음식을 더듬더 듬 찾는 행동이 있었고 준비한 떡을 약 5 분간 먹었으며 이후 바로 누운 채로 턱 움직임이 지속적으로 있었다(Fig. 2). 먹는

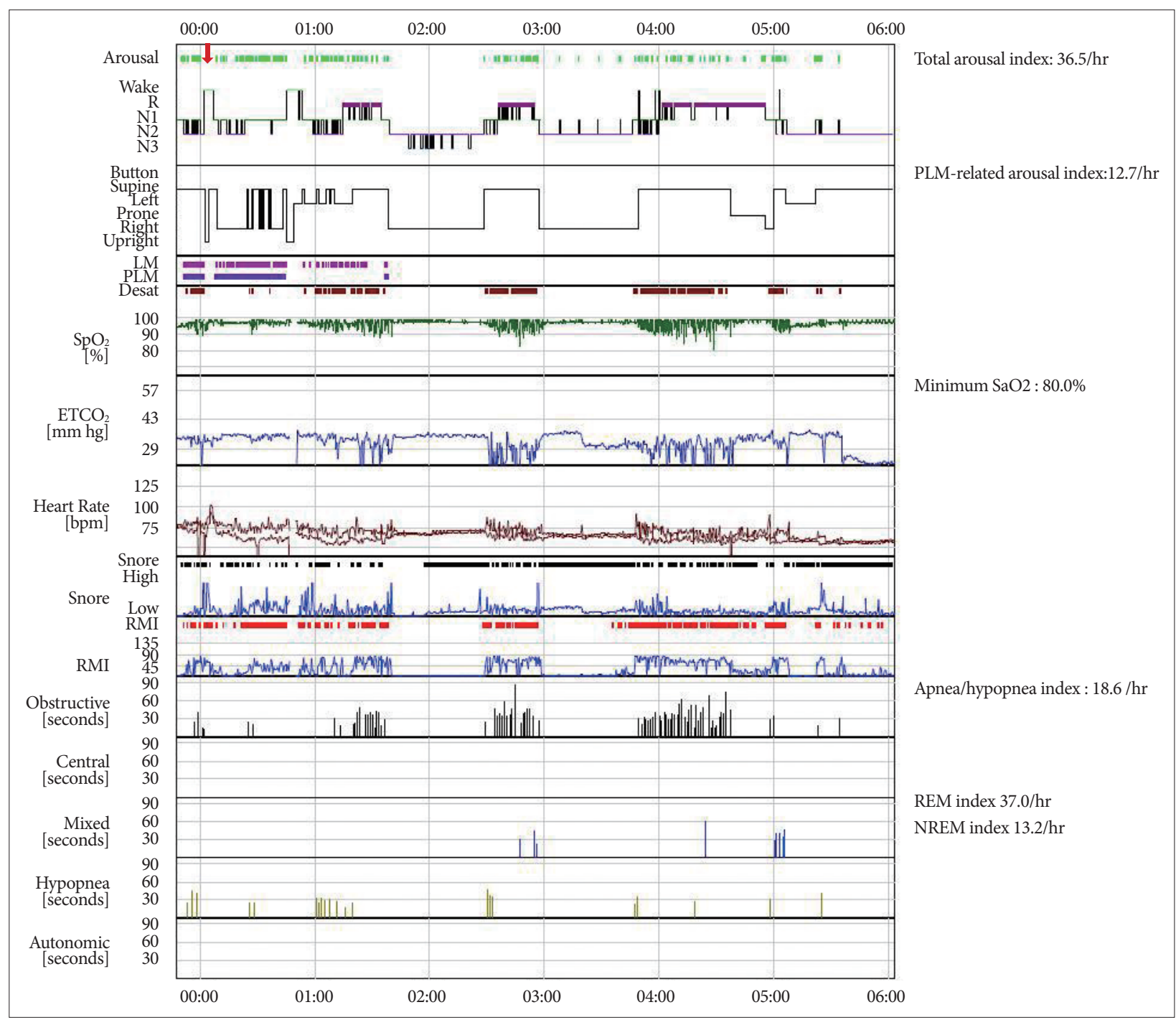

Fig. 1. Polysomnography of the patient. The patient had arousal event on $34 \mathrm{~min}$ after sleep onset. His AHI was 18.6/h (moderate sleep apnea) and PLM-related arousal index was $12.7 / \mathrm{hr}$. AHI: apnea/hypopnea index, PLM: periodic limb movement, REM: rapid eye movement, NREM: non-rapid eye movement, R: REM sleep, N1: non-REM sleep stage 1, LM: limb movement, $\mathrm{SpO}_{2}$ : pulse oximeter oxygen saturation, $\mathrm{ETCO}_{2}$ : end tidal $\mathrm{CO}_{2}$. 


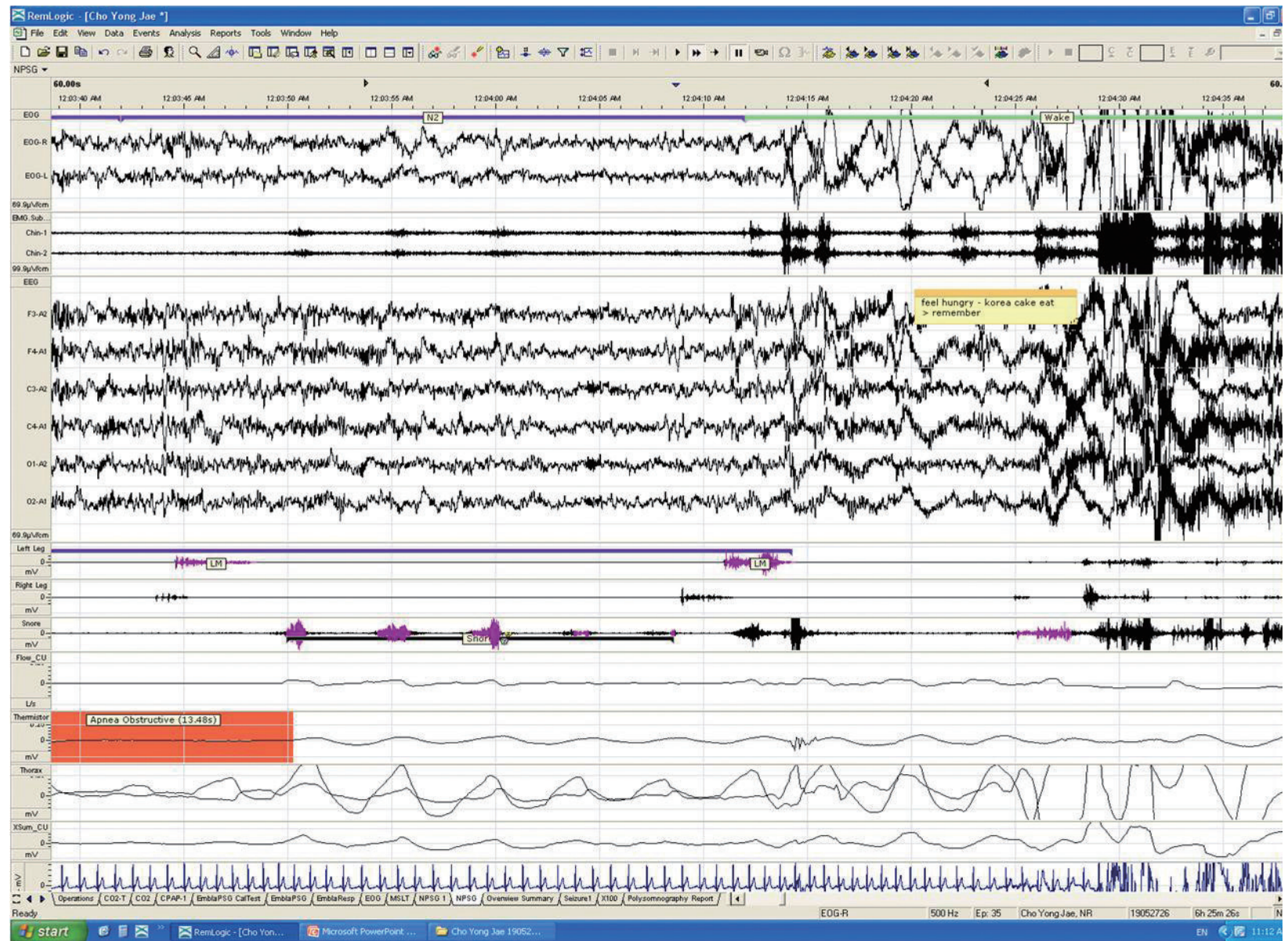

Fig. 2. Polysomnography raw data. The patient had arousal event on $34 \mathrm{~min}$ after sleep onset from NREM stage 2 . The eating event lasted for 5 min. NREM: non-rapid eye movement.

동작이 끝나면서 바로 NREM 1단계 수면 상태로 전환되었 다. 검사 이후 졸피뎀을 끊고 나서 수면 중 섭식 증상은 사라 졌다. 약과 관련된 문제로 생각되어 이후 불면증에 대해 아무 약도 먹지 않은 이후에 도리어 불면증이 호전되었으나 수면 무호흡증과 하지불안증후군은 지속적으로 호소하였다.

\section{고 찰}

본 증례에서 수면 중 각성을 동반하여 섭식이 일어나는 증 상에 대해 $\mathrm{SRED}$ 로 진단하였다. 이 증상은 졸피뎀을 사용한 후에 발생하였으며, 졸피뎀을 끊은 후 이 증상은 모두 사라져 졸피뎀 유발성 SRED로 진단하였다.

본 증례에서 환자는 우울감, RLS, 주간과다졸림증을 같이 호소하였고 수면다원검사상 수면무호흡증과 PLMS가 관찰 되었다. SRED 환자의 20 25\%에서 periodic limb movement 이 동반되어 있고 RLS, 수면무호흡증 등이 많이 동반되는 것 으로 보고되어 있다. ${ }^{4}$ 또한 도파민 계열의 약제를 투여했을 때 RLS, PLMS, SRED 증상이 호전을 보여 ${ }^{5}$ 모두 도파민 시
스템의 이상과 관련있는 것으로 보인다. 또한 섭식 추구 행 위(food seeking behavior)가 발생하는 것은 중간뇌변연섬유 신경로(mesolimbic pathway)의 보상작용의 기능 이상으로 인해 강박작용의 하나로 발현하는 것으로 생각하고 있다.

환자는 수면다원검사상 취침을 시작한지 30 분 이후에 먹 는 증상이 나타났으며 이는 졸피뎀을 투여한 후 1 2시간 이 내에 약효가 발현되는 것과 잘 맞는 소견이다. 평소 환자가 취침 후 2 시간 이내 증상이 발생한다고 보고하였는데 이는 졸피뎀이 최고 혈장 농도에 도달하는 시간이 1.2 시간, 반감기 가 2시간인 것과도 잘 부합한다. ${ }^{6}$ 졸피뎀은 벤조다이아제핀 이 아니면서도 벤조다이아제핀과 같이 GABAa 리셉터에 결 합하여 $\mathrm{GABA}$ 의 결합기능을 증가시키는 역할을 한다. 졸피 뎀은 벤조다이아제핀 결합 부위인 $\omega 1,2,3$ 중에 $\omega 1$ 에 선택적 으로 높은 결합력을 보여 벤조다이아제핀과 달리 항경련효 과, 항불안효과 없이 수면 유도 및 기억상실 효과만 나타내 게 된다. 졸피뎀 유발성 SRED에서는 졸피뎀의 이런 효과가 수면 중 섭취 증상에 대해 기억하지 못하게 하는 역할을 하 는 것으로 생각된다. 또한 졸피뎀이 과식 유도 효과가 있다는 
보고가 있고 이런 현상이 졸피뎀이 SRED를 발생시키는 것 에 영향을 주는 것으로 보인다. ${ }^{8}$

이상으로 졸피뎀 사용으로 유발된 SRED의 증례를 국내에 서 처음으로 보고하는 바이다. 졸피뎀은 불면증의 1 차치료 약제로서 가장 많이 사용되는 약물의 하나이나, 졸피뎀 사용 시 SRED 등의 complex sleep-related behavior가 발생할 가 능성이 있으므로 이에 대한 주의가 필요하겠다.

\section{REFERENCES}

1. Schenck CH, Hurwitz TD, Bundlie SR, Mahowald MW. Sleep-related eating disorders: polysomnographic correlates of a heterogeneous syndrome distinct from daytime eating disorders. Sleep 1991;14:419-431.

2. Vetrugno R, Manconi M, Ferini-Strambi L, Provini F, Plazzi G, Montagna $P$. Nocturnal eating: sleep-related eating disorder or night eating syn- drome? A videopolysomnographic study. Sleep 2006;29:949-954.

3. Morgenthaler TI, Silber MH. Amnestic sleep-related eating disorder associated with zolpidem. Sleep Med 2002;3:323-327.

4. Winkelman JW. Clinical and polysomnographic features of sleep-related eating disorder. JClin Psychiatry 1998;59:14-19.

5. Schenck CH, Hurwitz TD, O'Connor KA, Mahowald MW. Additional categories of sleep-related eating disorders and the current status of treatment. Sleep 1993;16:457-466.

6. Hoque R, Chesson AL Jr. Zolpidem-induced sleepwalking, sleep related eating disorder, and sleep-driving: fluorine-18-flourodeoxyglucose positron emission tomography analysis, and a literature review of other unexpected clinical effects of zolpidem. J Clin Sleep Med 2009;5:471-476.

7. Dang A, Garg A, Rataboli PV. Role of zolpidem in the management of insomnia. CNS Neurosci Ther 2011;17:387-397.

8. Mitchell CP, Ost ML, Flaherty CF. Evidence for zolpidem-induced hyperphagia, but not anxiolysis, in a successive negative contrast paradigm. Pharmacol Biochem Behav 2004;79:523-531. 